\title{
Influenza and Influenza-Like Illnesses in Poland in the Epidemic Season 2010/2011 According to the SENTINEL Influenza Surveillance System
}

\author{
MAGDALENA ROMANOWSKA ${ }^{1 *}$, ILONA STEFAŃSKA ${ }^{1,2}$ and LIDIA B. BRYDAK ${ }^{1,3}$ \\ ${ }^{1}$ Department of Influenza Research. National Influenza Centre, \\ National Institute of Public Health-National Institute of Hygiene, Warsaw, Poland \\ ${ }^{2}$ Department of Fermentation Technology, Institute of Agricultural and Food Biotechnology, Warsaw, Poland \\ ${ }^{3}$ Faculty of Biology, Department of Immunology, University of Szczecin, Szczecin, Poland
}

Received 2 July 2012, revised 30 October 2012, accepted 15 November 2012

\section{Abstract}

The aim of this study was to analyze data collected by the SENTINEL influenza surveillance system in Poland in the first post-pandemic season 2010/2011. The results include weeks 35/2010-17/2011. Physicians registered weekly number of influenza-like illnesses and collected specimens. Laboratory tests were done using PCR and/or real-time PCR or immunofluorescence. Laboratories also isolated the influenza virus. Influenza-like illness incidence amounted to 2802.7/100000. Weekly incidence ranged from 11.3/100000 to 232/100000. The most affected group was children 0-4 years. Influenza-like illness peak occurred between weeks 02/2011 and 11/2011. Influenza infections were confirmed in $34.9 \%$ of specimens. More cases were caused by influenza A, including A(H1N1)pdm09 than influenza B (59.9\% vs. 40.1\%). The isolated strains were similar to A/California/7/2009 or B/Brisbane/60/2008. Season 2010/2011 in Poland did not differ from the rest of Europe. Further improvement is necessary, especially in the area of specimen collection at the beginning of an epidemic season and carrying out the isolation of the influenza virus.

Ke y w o rds: A(H1N1)pdm09, diagnostics, influenza, respiratory viruses, sentinel, surveillance

\section{Introduction}

Millions of influenza illnesses, thousands to millions of deaths registered every year as well as threat of the next pandemic and human infections with highly pathogenic avian viruses as $\mathrm{A}(\mathrm{H} 5 \mathrm{~N} 1)$, make influenza still one of the public health priorities. Effective influenza control depends on many factors, including surveillance that should focus on the collection of epidemiological data and virological data (laboratory confirmations of infections) in a given population during a given period of time (WHO, 2011a). Surveillance data is not only limited to its informative role, but is practically used by decision makers to implement appropriate interventions to stop or to minimize negative effects of the forthcoming epidemic or pandemic. This data is also used to assess impact of epidemic or pandemic and is necessary for $\mathrm{WHO}$ to select appropriate virus strains to be included in the influenza vaccine and to assess the effectiveness of antivirals or to develop new drugs. It should be emphasized that in the case of influenza, surveillance is extremely important also due to a high level of changeability of influenza viruses (Webster et al., 1992; Murphy and Webster, 1996; Cox and Subbarao, 2000). The consequences of these changes are seasonal epidemics and pandemics having a health and economic impact. Therefore, in a given epidemic season, influenza strains antigenically different than those in the previous seasons may emerge. This may have consequences for morbidity, mortality, number of complications and economic burden. Therefore, monitoring of epidemiological and virological situation must be performed as a constant task. In temperate zones of north and south hemispheres, the highest influenza activity is observed in winter months (Nguyen-VanTam, 1998). Nevertheless, nowadays borders as well as distances of hundreds or thousands of kilometers are not a barrier for the spread of infections. Therefore, surveillance of a high quality should exist in each country and should be performed preferably all year round. The

* Corresponding author: M. Romanowska, Department of Influenza Research. National Influenza Centre, National Institute of Public Health-National Institute of Hygiene, 24 Chocimska Street, 00-791 Warsaw, Poland; phone +48 6934255 65; e-mail: magdalena. machalaromanowska@gmail.com 
significance of influenza surveillance was clearly proved in 2009. In that time, a novel influenza virus $\mathrm{A}(\mathrm{H} 1 \mathrm{~N} 1)$ of swine origin emerged and in the end of April 2009 quickly spread to Europe when a typical influenza epidemic season had just ended (ECDC, 2010a; ECDC, 2010b; Neumann and Kawaoka, 2011).

The aim of this study was to analyse virological and epidemiological data derived from the SENTINEL influenza surveillance system in Poland in the first epidemic season after the $2009 \mathrm{H} 1 \mathrm{~N} 1$ influenza pandemic.

\section{Experimental}

\section{Materials and Methods}

Results presented in this paper include 35 weeks of the epidemic season 2010/2011 (35/2010-17/2011), i.e. period between 30 August 2010 and 1 May 2011. They were collected through the SENTINEL influenza surveillance system that was established in 2004 and started to operate in the season 2004/2005 (Romanowska et al., 2008a). The participants of this system are: a selected number of general practitioners, Voivodship Sanitary Epidemiological Stations (VSESs) located in 16 administrative regions (voivodships) and the National Influenza Centre (NIC) at the Dept. of Influenza Research, National Institute of Public Health-National Institute of Hygiene (NIPH-NIH), Warsaw. Physicians registered weekly number of new cases of influenza-like illness (ILI) and collected specimens for laboratory testing, mainly nasal and throat swabs. Laboratory tests were done by the VSESs. For the rapid diagnostics the following methods were used depending on their availability in a given VSES: polymerase chain reaction (PCR) and/or real-time PCR and/or direct immunofluorescence test. The VSESs were asked to perform diagnostics for influenza as well as other respiratory viruses causing influenza-like illness as RSV, parainfluenza virus (types 1-3) and adenovirus. Besides, all VSESs were obliged to perform isolation of influenza virus on MDCK cell line and/or chicken embryonated eggs. VSESs sent weekly epidemiological and virological reports to the NIC at NIPH-NIH as well as isolated virus strains for antigenic analysis. The latter was performed by hemagglutination inhibition test with turkey red blood cells and reference ferret and sheep antisera received from WHO Collaborating Centre for Reference and Research on Influenza in London and from Centers for Disease Control and Prevention in Atlanta.

Every week, the NIC at NIPH-NIH entered epidemiological and virological data to The European Surveillance System (TESSy) coordinated by the European Centre for Disease Prevention and Control (ECDC) as well as to FluNet coordinated by WHO. Moreover, viro- logical data were included in "Epidemiological Reports. Influenza and influenza-like illness in Poland" published four times a month and available online (http:// www.pzh.gov.pl/oldpage/epimeld/grypa/aindex.htm).

\section{Results}

In the epidemic season 2010/2011, SENTINEL influenza surveillance system covered a population of 1268737 individuals, i.e. $3.3 \%$ of the total country population. Considering particular age groups, SENTINEL included 72078 children aged up to 4 years (3.6\% of all children at this age), 156261 children aged 5-14 years (4.2\% of all children at this age), 859061 people aged $15-64$ (3.1\% of all people at this age) and 181336 elderly aged $\geq 65$ years $(3.5 \%$ of all people at this age). Characteristics of the SENTINEL system as regards population covered in individual administrative regions is presented in Table I.

Epidemiological data were provided by 640 physicians (587 to 668 depending on the week), i.e. $0.5 \%$ of the total number of physicians in the country except of dentists, representing 269 practices. Between week $35 / 2010$ and 17/2011 a total number of 35559 ILI cases were registered with the incidence amounting to 2802.7 per 100000 . Weekly incidence ranged from 11.3 per 100000 in week $17 / 2011$ to 232.0 per 100000 in week $05 / 2011$. The highest incidence was registered in children up to 4 years old while the lowest in the elderly aged $\geq 65$ years. The peak of the influenza season was observed between 10 January 2011 and 20 March 2011, i.e. in weeks 02/2011-11/2011 (Fig. 1).

The total number of specimens collected and processed within the SENTINEL influenza surveillance system was 1259 . Infections caused by the influenza virus or other respiratory viral pathogens as RSV, parainfluenza and adenovirus were confirmed in 468 cases (37.2\%). Taking into consideration only influenza infections, they were laboratory confirmed in $34.9 \%$ $(n=440)$ of all specimens collected. Distribution of positive cases is presented in Table II. Two of three coinfections were caused by parainfluenza virus type 1 and type 3, while one co-infection was caused by influenza virus $\mathrm{A}$ and $\mathrm{B}$.

In weeks $35 / 2010,16 / 2011$ and $17 / 2011$ no specimens were received for testing. The most specimens were collected between week $02 / 2011$ and week 10/2011 (10 January 2011 until 13 March 2011) with the highest number of confirmed cases of influenza as well as other respiratory viruses registered in that period (Fig. 2, Table III).

Taking into consideration all influenza infections, the higher number of cases were caused by influenza $\mathrm{A}$ virus, including $\mathrm{A}(\mathrm{H} 1 \mathrm{~N} 1)$ pdm09 than by influenza $\mathrm{B}$ 
Table. I

Population covered by the SENTINEL influenza surveillance system in individual administrative regions in the epidemic season 2010/2011.

\begin{tabular}{|l|c|c|}
\hline $\begin{array}{c}\text { Administrative region (voivodship) } \\
\text { and its provincial capital }\end{array}$ & $\begin{array}{c}\text { Voivodship population } \\
\text { covered by the SENTINEL } \\
\text { influenza surveillance system }\end{array}$ & $\begin{array}{c}\text { Proportion (\%) of the total } \\
\text { voivodship population }\end{array}$ \\
\hline Dolnośląskie / Wroclaw & 62446 & 2.2 \\
\hline Kujawsko-Pomorskie / Bydgoszcz & 309191 & 14.9 \\
\hline Lubelskie / Lublin & 147867 & 6.9 \\
\hline Lubuskie / Gorzow Wielkopolski & 54034 & 5.3 \\
\hline Łódzkie / Lodz & 29133 & 1.1 \\
\hline Malopolskie / Krakow & $2706^{\mathrm{a}}$ & 0.1 \\
\hline Mazowieckie / Warszawa & 63628 & 1.2 \\
\hline Opolskie / Opole & 110200 & 10.7 \\
\hline Podkarpackie / Rzeszów & 55909 & 2.7 \\
\hline Podlaskie / Białystok & 38855 & 3.3 \\
\hline Pomorskie / Gdańsk & 150210 & 6.7 \\
\hline Śląskie / Katowice & 28193 & 2.3 \\
\hline Świętokrzyskie / Kielce & 29037 & 1.0 \\
\hline Warmińsko-Mazurskie / Olsztyn & 14465 & 3.5 \\
\hline Wielkopolskie / Poznań & 120090 & 3.3 \\
\hline Zachodniopomorskie / Szczecin & 55265 & \\
\hline
\end{tabular}

a in the epidemic season 2010/2011, the participation of this voivodship in the SENTINEL influenza surveillance system was very limited to two physicians when compared with the previous seasons

(59.9\% vs. $40.1 \%)$. Analyzing data by weeks, influenza A infections were dominant until week 08/2011, while influenza B infections become dominant from week 09/2011 (Fig. 3).
In the epidemic season 2010/2011, isolation of 15 influenza virus strains within the SENTINEL influenza surveillance system was confirmed by the NIC at the Dept. of Influenza Research, NIPH-NIH. There

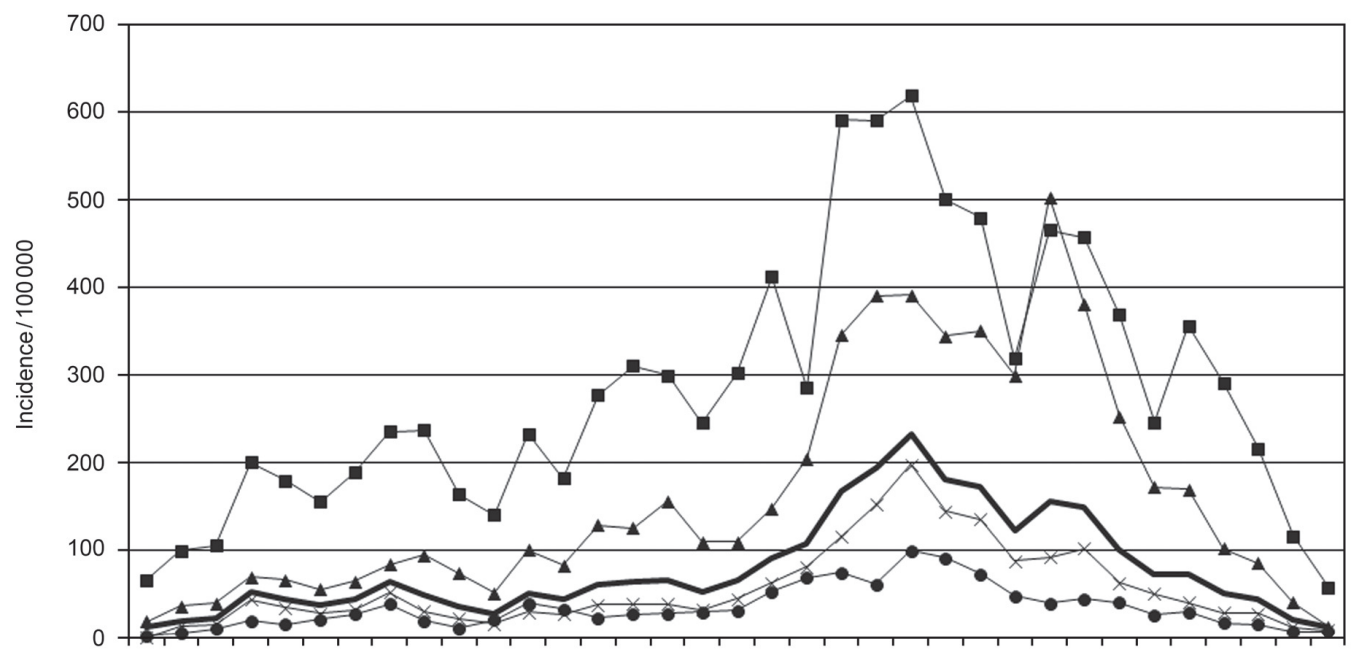

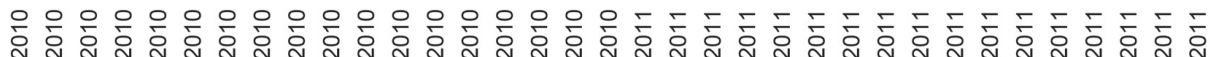

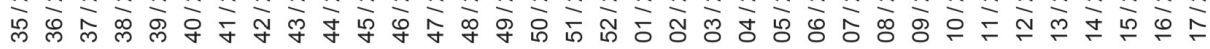
week

$$
\longrightarrow \text { total } \rightarrow \text { 0-4 years } \leftarrow \text { 5-14 years } \nleftarrow \text { 15-64years } \rightarrow-265 \text { years }
$$

Fig. 1. Incidence of influenza by weeks of the epidemic season 2010/2011. 


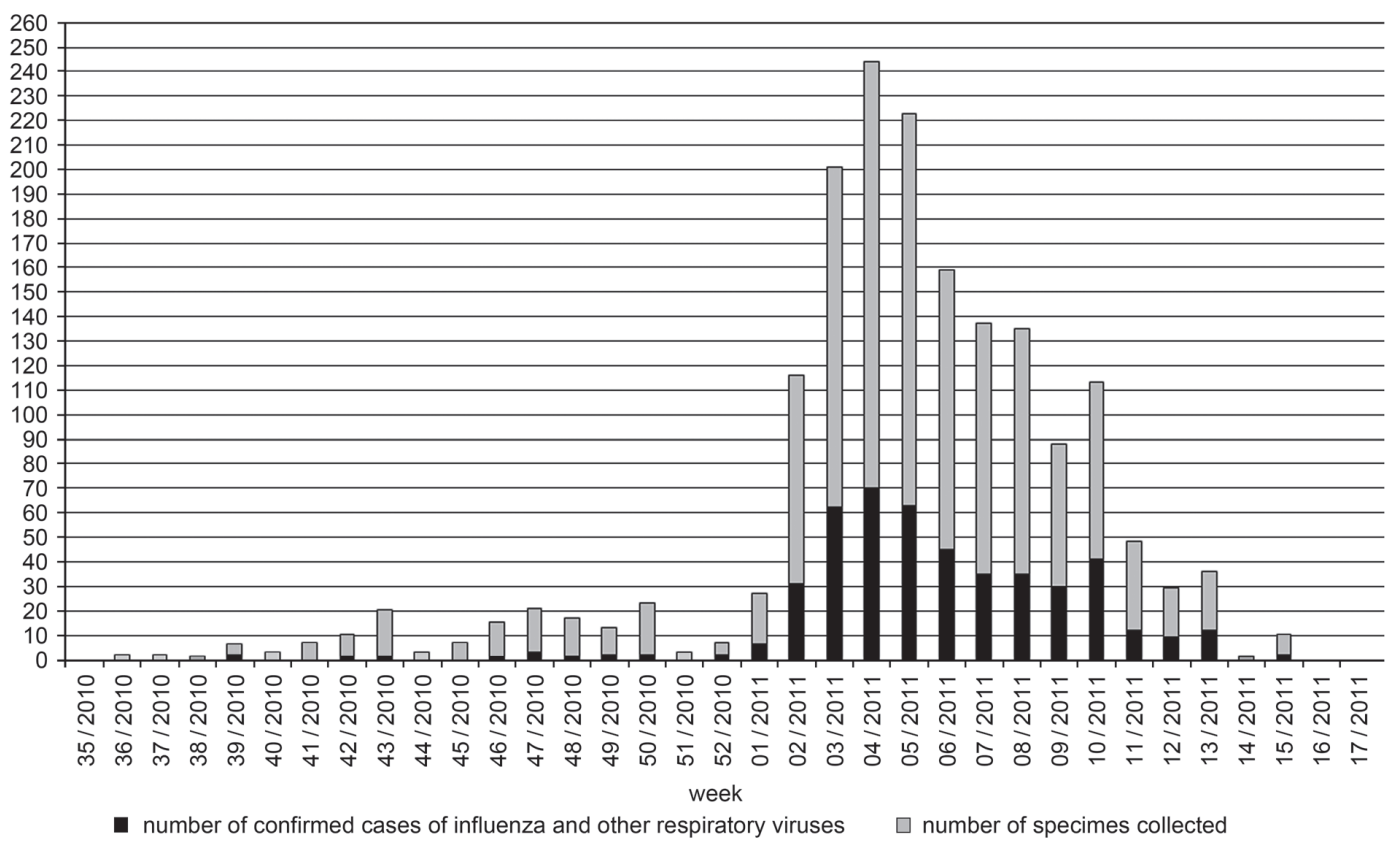

Fig. 2. Weekly number of the processed specimens and the proportion of the confirmed cases of influenza and other respiratory viruses.
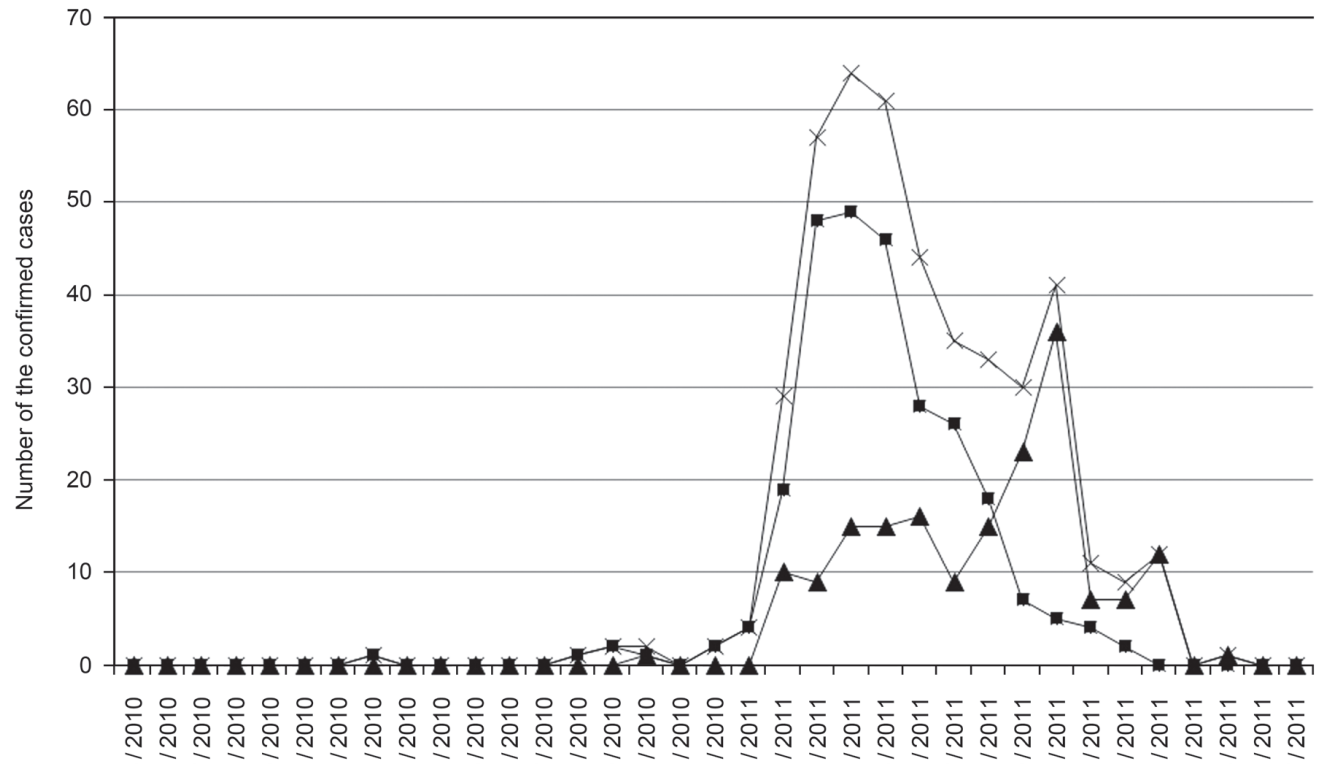

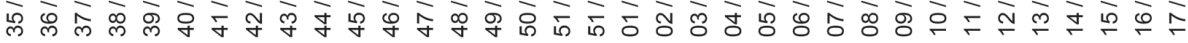

$\rightarrow$ influenza A

Fig. 3 Weekly proportion of the confirmed cases of influenza A and influenza B.

were 3 strains antigenically similar to A/California/7/2009 (H1N1) and 12 strains similar to B/Brisbane/60/2008. All of them were isolated on MDCK cell culture from patients representing 5 of 16 administrative regions.

\section{Discussion}

The highest rate of influenza morbidity occurred in children aged $0-4$ years and also in children aged 5-14 years and this was consistent with the observa- 
Table II

Distribution of positive SENTINEL cases of influenza and other respiratory viruses in Poland in the epidemic season 2010/2011

\begin{tabular}{|l|r|c|}
\hline \multicolumn{1}{|c|}{ Viral pathogen } & $\begin{array}{c}\text { Number } \\
\text { of }^{\text {cases }}{ }^{\mathrm{a}}\end{array}$ & $\begin{array}{c}\text { Proportion (\%) of the } \\
\text { total positive cases }\end{array}$ \\
\hline Influenza A (not subtyped) & 38 & 8.1 \\
\hline Influenza A(H1N1)pdm09 & 226 & 48.3 \\
\hline Influenza A(H1N1) & 0 & 0 \\
\hline Influenza A(H3N2) & 0 & 0 \\
\hline Influenza B & 177 & 37.8 \\
\hline RSV & 13 & 2.8 \\
\hline Parainfluenza type 1 & 9 & 1.9 \\
\hline Parainfluenza type 2 & 0 & 0 \\
\hline Parainfluenza type 3 & 3 & 0.6 \\
\hline Adenovirus & 5 & 1.1 \\
\hline
\end{tabular}

a three cases of co-infections were included

tions made in the majority of other European countries in the epidemic season 2010/2011 as well as in the previous seasons (ECDC, 2007; ECDC, 2008; ECDC, 2010c; ECDC, 2010d; ECDC, 2011a; ECDC, 2011b). A total number of ILI cases and influenza incidence were lower than in the 2009/2010 pandemic season ( 35559 vs. 58065 of ILI cases and 2802.7 cases per 100000 vs. 3676.0 cases per 100000 in 2010/2011 and $2009 / 2010$, respectively). This decrease of ILI incidence and the number of cases in comparison with the season 2009/2010 may reflect the true epidemiological situation. Nevertheless, it cannot be excluded that during the pandemic season, patients more willingly visited physicians and did not ignore even mild symptoms of disease considering pandemic influenza virus as a serious threat for their health and life as opposed to seasonal influenza viruses.

The peak of ILI activity in the epidemic season 2010/2011 (weeks 01/2011-11/2011 with the highest incidence amounting to 232.0 per 100000 in week 05/2011) did not occur as early as during the previous 2009/2010 season (weeks 44/2009-52/2009 with the highest incidence amounting to 353.0 per 100000 in week 48/2009). Similar trend was registered in other European countries (ECDC, 2011a; ECDC, 2011b; WHO, 2011b). In Poland, epidemiological data collected by the SENTINEL system since the epidemic season $2004 / 2005$ show that the peak of influenza season usually occurs between week no. 03 and week no. 12, i.e. between the end of January and March (Romanowska et al., 2008a; Romanowska et al., 2008b). These findings are also confirmed by the epidemiological data collected by the national universal system of surveillance of infectious diseases, including influenza (Brydak, 2008). Thus, the epidemic season 2010/2011 in Poland may be considered as typical when compared with the
Table III

Weekly proportions of the SENTINEL confirmed infections of influenza and other respiratory viruses in Poland in the epidemic season 2010/2011.

\begin{tabular}{|c|c|c|c|}
\hline $\begin{array}{c}\text { No. } \\
\text { of week }\end{array}$ & $\begin{array}{l}\text { Number of } \\
\text { specimens } \\
\text { collected } \\
\text { and } \\
\text { processed }\end{array}$ & $\begin{array}{l}\text { Weekly propor- } \\
\text { tion (\%) of the } \\
\text { confirmed } \\
\text { infections with } \\
\text { influenza virus }\end{array}$ & $\begin{array}{l}\text { Weekly proportion } \\
\text { (\%) of the confirmed } \\
\text { infections with } \\
\text { influenza and other } \\
\text { respiratory viruses }\end{array}$ \\
\hline $35 / 2010$ & 0 & 0.0 & 0.0 \\
\hline $36 / 2010$ & 2 & 0.0 & 0.0 \\
\hline $37 / 2010$ & 2 & 0.0 & 0.0 \\
\hline $38 / 2010$ & 1 & 0.0 & 0.0 \\
\hline $39 / 2010$ & 4 & 0.0 & 50.0 \\
\hline $40 / 2010$ & 3 & 0.0 & 0.0 \\
\hline $41 / 2010$ & 7 & 0.0 & 0.0 \\
\hline $42 / 2010$ & 9 & 11.1 & 11.1 \\
\hline $43 / 2010$ & 19 & 0.0 & 5.3 \\
\hline $44 / 2010$ & 3 & 0.0 & 0.0 \\
\hline $45 / 2010$ & 7 & 0.0 & 0.0 \\
\hline $46 / 2010$ & 14 & 0.0 & 7.1 \\
\hline $47 / 2010$ & 18 & 0.0 & 16.7 \\
\hline $48 / 2010$ & 16 & 6.3 & 6.3 \\
\hline $49 / 2010$ & 11 & 18.2 & 18.2 \\
\hline $50 / 2010$ & 21 & 9.5 & 9.5 \\
\hline $51 / 2010$ & 3 & 0.0 & 0.0 \\
\hline $52 / 2010$ & 5 & 40.0 & 40.0 \\
\hline $01 / 2011$ & 21 & 19.0 & 28.6 \\
\hline $02 / 2011$ & 85 & 34.1 & 36.5 \\
\hline $03 / 2011$ & 139 & 41.0 & 44.6 \\
\hline $04 / 2011$ & 174 & 36.8 & 40.2 \\
\hline $05 / 2011$ & 160 & 38.8 & 39.4 \\
\hline $06 / 2011$ & 114 & 38.6 & 39.5 \\
\hline $07 / 2011$ & 102 & 34.3 & 34.3 \\
\hline $08 / 2011$ & 100 & 33.0 & 35.0 \\
\hline $09 / 2011$ & 58 & 51.7 & 51.7 \\
\hline $10 / 2011$ & 72 & 56.9 & 56.9 \\
\hline $11 / 2011$ & 36 & 30.6 & 33.3 \\
\hline $12 / 2011$ & 20 & 45.0 & 45.0 \\
\hline $13 / 2011$ & 24 & 50.0 & 50.0 \\
\hline $14 / 2011$ & 1 & 0.0 & 0.0 \\
\hline $15 / 2011$ & 8 & 12.5 & 25.0 \\
\hline $16 / 2011$ & 0 & 0.0 & 0.0 \\
\hline $17 / 2011$ & 0 & 0.0 & 0.0 \\
\hline
\end{tabular}

${ }^{a}$ RSV, parainfluenza virus type 1, parainfluenza virus type 2, parainfluenza virus type 3 , adenovirus

historical data. These data, together with information from other European countries, also confirm the westeast transmission of influenza infection in Europe that is observed at least since the epidemic season 2001/2002 (ECDC, 2010c; ECDC, 2010d; ECDC, 2011a; ECDC, 2011b; WHO, 2011b; Paget et al., 2007). 
In the whole epidemic season 2010/2011, the total rate of detection of influenza alone or influenza together with other respiratory viruses exceeded 30\% (34.9\% and $37.2 \%$, respectively). When considering data for the entire Europe, the detection rate of influenza infections was similar and amounted to $39.8 \%$ (ECDC, 2011b). It should be noticed that since the epidemic season $2004 / 05$, i.e. the first season of existence of the SENTINEL influenza surveillance in Poland, until the beginning of the last influenza pandemic caused by $\mathrm{A}(\mathrm{H} 1 \mathrm{~N} 1) \mathrm{pdm} 09$ virus, the percentage of specimens tested positive for influenza ranged from $3.1 \%$ to $15.8 \%$ (Romanowska et al., 2008a; Romanowska et al., 2008b; Romanowska et al., 2010). These five epidemic seasons (2004/2005-2008/2009) suggest that the collection and storage of specimens and/or methods of virus detection together with their sensitivity and specificity as well as the quality of test performance were not always optimal. These weaknesses might refer to the regional laboratories performing diagnostics as well as to the SENTINEL physicians who have to recognize influenza-like illness cases and collect specimens only from patients meeting appropriate criteria. The NIC, NIPH-NIH prepared technical instructions how to perform SENTINEL influenza surveillance in a given epidemic season and sent to the VSESs. The VSESs forwarded these instructions to the SENTINEL physicians and often organized meetings with them before start of a given epidemic season. Despite the above activities, a significant increase of the detection rate was observed during the last pandemic season 2009/2010 when influenza infection alone was confirmed in $26.8 \%$, while influenza with other respiratory viruses - in $32.7 \%$ of the SENTINEL specimens (data not published). Luckily, this positive increasing trend was maintained and observed also in the first post-pandemic season 2010/2011 described in this paper. This may be due to a greater intensity of influenza circulation as well as improvement in the sensitivity of laboratory methods used for diagnostics. Until the epidemic season 2009/2010, detection of influenza and other respiratory viruses in specimens collected from ILI cases was mainly based on immunofluorescence assay that was performed directly or on $24-48 \mathrm{~h}$ cultured specimens, and virus isolation methods. During the pandemic of $\mathrm{A}(\mathrm{H} 1 \mathrm{~N} 1) \mathrm{pdm} 09$, many of the VSESs received additional funds and were able to improve its laboratory facilities and introduced methods of molecular detection, based on PCR. Since then and throughout the epidemic season 2010/2011, PCR was the main laboratory method used in influenza surveillance.

The highest number of specimens tested positive for influenza or other respiratory viruses were collected between week no. 02/2011 and week no. 10/2011. This time period is consistent with the peak of ILI incidence indicating quite a good integration of epidemical sur- veillance with virological surveillance that is one of the most important principles of the SENTINEL influenza surveillance systems (Fleming, et al., 2003; EISS, 2006).

As written earlier, in the epidemic season 2010/2011 the peak of influenza activity occurred nine weeks later than in the 2009/2010 pandemic season (weeks 44/2009-52/2009). The first positive influenza A SENTINEL specimen was registered in week no. 42/2010 (influenza A not subtyped) and influenza B in week no. $50 / 2010$, whereas in the previous season, the $\mathrm{A}(\mathrm{H} 1 \mathrm{~N} 1)$ pdm09 virus began to circulate before the start of the usual influenza season and first influenza B virus was reported in week no. 45/2009.

Analyzing virological data, the 2010/2011 influenza epidemic season in Poland was characterized by predominance of influenza A viruses (263 cases), but in contrast to the previous season 2009/2010, the high rate of co-circulation with influenza B viruses (176 cases) was observed. Among SENTINEL specimens positive for influenza A, 226 were positive for $\mathrm{A}(\mathrm{H} 1 \mathrm{~N} 1)$ pdm09 and 37 were not subtyped. No seasonal influenza $\mathrm{A}(\mathrm{H} 3 \mathrm{~N} 2)$ and the previously circulating $\mathrm{A}(\mathrm{H} 1 \mathrm{~N} 1)$ viruses were detected.

When analyzing a distribution of different influenza viruses, the peak of influenza type A activity occurred between week 02/2011 and week 08/2011 and preceded the peak of influenza type B activity, which was observed between week no. 04/2011 and week no. 13/2011. There was a period when activity of both $A$ and $B$ viruses was high and overlapped (weeks 04/2011-08/2011). Dating from week 09/2011, influenza type B became predominant virus detected and almost replaced influenza $\mathrm{A}$ in the last weeks of the season.

In the epidemic season 2010/2011, there was some variation in influenza activity and dominant viruses registered by the SENTINEL influenza surveillance systems in the other European countries (EuroFlu Weekly Electronic Bulletins available on http://www.euroflu. org/cgi-files/bulletin_v2.cgi). Nevertheless, Polish data corresponds to virological situation in majority of them where the co-circulation of influenza $A$ and $B$ viruses with domination of influenza $\mathrm{A}(\mathrm{H} 1 \mathrm{~N} 1)$ pdm09 lasting until the week 06/2011 was observed (ECDC, 2011b). After week no. 06/2011 influenza B viruses became predominant in Europe, however in some countries influenza B was the most commonly detected influenza virus type (Norway, Romania, Sweden, Ukraine and Scotland) or influenza A and influenza B were reported as co-dominant viruses (Luxemburg, the Netherlands, Italy, Turkey and Slovenia). In contrast, in Israel, Portugal and Ukraine influenza B started to circulate before influenza A, and the peak of influenza B activity occurred earlier when compared with influenza A (Portugal, Ukraine). Some countries reported very low influenza $\mathrm{B}$ activity (a single positive specimens in indi- 
vidual weeks) and thus, there was no apparent peak for influenza B viruses (Greece, Slovakia, Serbia and Estonia) or did not report any influenza B cases throughout the entire epidemic season (Denmark, Cyprus) (based on the EuroFlu Weekly Electronic Bulletins available on http://www.euroflu.org/cgi-files/bulletin_v2.cgi).

According to the SENTINEL surveillance data, the vast majority of influenza A detections in Europe were influenza $\mathrm{A}(\mathrm{H} 1 \mathrm{~N} 1) 09 \mathrm{pdm}$ (97\% of influenza A subtyped viruses) and influenza B activity was much higher than that seen during the pandemic 2009/2010 season (ECDC, 2011b). Influenza A(H3N2) strains were relatively uncommon in Europe (3\% of the subtyped influenza A viruses) and some cases were isolated in e.g. France, Germany, Greece, Italy, Norway, Serbia, Spain, Sweden, Turkey (based on the EuroFlu Weekly Electronic Bulletins available on http://www. euroflu.org/cgi-files/bulletin_v2.cgi and WHO Influenza update - 25 March 2011 available on http:// www.who.int/influenza/surveillance_monitoring/ updates/2011_03_25_GIP_surveillance/en/index. html\#). None of the previously circulating A(H1N1) viruses were detected in any European countries, including Poland (ECDC, 2011b). In contrast to Europe, influenza $\mathrm{A}(\mathrm{H} 3 \mathrm{~N} 2)$ was the most commonly circulating virus in Mexico, USA and Canada throughout the epidemic season (WHO, 2011b).

Data presented in this study show that respiratory viruses other than influenza were detected only in 28 cases. This number is probably underestimated mainly due to the methods used in diagnostics. Detection of influenza viruses was performed mostly using PCR or real-time PCR, whereas the identification of other respiratory viruses was performed by immunofluorescence assay that is far less sensitive than molecular methods. Besides, despite the recommendations of the NIC, NIPH-NIH, some proportion of the collected specimens were tested only for influenza viruses due to the economic reasons.

Similarly to other European countries, the results of antigenic analysis indicate a good match between all Polish isolates and reference viruses recommended by WHO for inclusion in a trivalent influenza vaccine for use in the 2010/2011 season (WHO, 2010).

In Poland, all isolated strains of subtype A(H1N1) pdm09 were antigenically characterized as similar to the pandemic A/California/7/2009-like viruses, and all influenza B strains were antigenically similar to B/ Brisbane/60/2008-like viruses (B/Victoria/2/87 lineage). At the European level, all isolated influenza A strains were antigenically characterized as similar to the vaccine strains recommended for the season 2010/2011, i.e. to A/California/7/2009 (H1N1)-like viruses or A/ Perth/16/2009 (H3N2)-like viruses. In the case of influenza B isolates, $91.3 \%$ of them belonged to the Victoria lineage and were similar to the vaccine strain $\mathrm{B} /$ Brisbane $/ 60 / 2008$, while the remaining $8.7 \%$ of isolates were similar to viruses from the B/Yamagata/16/88 lineage.

Summarizing, the picture of the epidemic season 2010/2011 in Poland did not differ from the general observations made for the rest of Europe in the terms of the most affected age groups, time of the peak influenza activity, detection rate of influenza infections, dominant types of influenza viruses circulating in a different periods of the season and antigenic characteristics of the isolated influenza virus strains. On the one hand the collected epidemiological and virological data allowed to describe influenza activity in the first post-pandemic season, but on the other hand they simultaneously indicated some areas in which a further improvement is necessary to have representative surveillance of a high quality in Poland. Data presented in the first part of the results show that the general representativeness of the individual age groups in the SENTINEL influenza surveillance system in Poland is quite regular ranging from $3.1 \%$ to $4.2 \%$ of all people at the given age group. Nevertheless, between individual voivodships there is a big dispersion in the proportion of the total voivodship population covered by the SENTINEL surveillance that ranged from $1.0 \%$ up to $14.9 \%$. The other area for the improvement regards the collection of the specimens in the beginning of the epidemic season as one of the aims of surveillance is to identify the start of the season. The third issue is to encourage regional laboratories of the VSESs to focus more actively on the isolation of influenza viruses on cell lines or chicken embryos, and not to replace this technique by PCR methods. The forthcoming influenza epidemic seasons will show whether the above weaknesses are eliminated. Nevertheless, this can be difficult until the SENTINEL influenza surveillance system is based on the voluntary basis and no legal regulations and specific funding for this aim exist.

\section{Acknowledgements}

The authors would like to thank the staff of sixteen Voivodship Sanitary Epidemiological Stations as well as physicians for their contribution in the SENTINEL influenza surveillance system in the epidemic season 2010/2011. Special thanks are due to Ms Dorota Urszula Ostapiuk from the Dept. of Influenza Research. National Influenza Centre, National Institute of Public Health-National Institute of Hygiene for her technical assistance.

\section{Literature}

Brydak L.B. 2008. Influenza. Pandemic influenza - myth or real threat? (Grypa. Pandemia grypy - mit czy realne zagrożenie?). $1^{\text {st }} \mathrm{ed}$. Rytm, Warsaw.

Cox N.J. and K. Subbarao. 2000. Global epidemiology of influenza: past and present. Annu. Rev. Med. 51: 407-421. 
ECDC (European Centre for Disease Prevention and Control). 2007. Annual epidemiological report on communicable diseases in Europe 2005. Stockholm: ECDC, pp. 1-301. Available from: http:// www.ecdc.europa.eu/en/publications/Publications/0706_SUR_ Annual_Epidemiological_Report_2007.pdf

ECDC (European Centre for Disease Prevention and Control). 2008. Annual epidemiological report on communicable diseases in Europe 2008. Stockholm: ECDC, pp. 1-320. Available from: http:// www.ecdc.europa.eu/en/publications/Publications/0812_SUR_ Annual_Epidemiological_Report_2008.pdf

ECDC (European Centre for Disease Prevention and Control). 2010a. European 2009 influenza pandemic timeline. ECDC Influenza Programme. 2010 Aug 11: 1-11. Available from: http://www. ecdc.europa.eu/en/healthtopics/H1N1/Documents/110810_2009_ pandemic_European_Timeline.pdf

ECDC (European Centre for Disease Prevention and Control). 2010b. ECDC special report. The $2009 \mathrm{~A}(\mathrm{H} 1 \mathrm{~N} 1)$ pandemic in Europe. A review of the experience. ECDC. 2010 Nov: 1-48. Available from: http://www.ecdc.europa.eu/en/publications/Publications/101108_SPR_pandemic_experience.pdf

ECDC (European Centre for Disease Prevention and Control). 2010c. Annual epidemiological report on communicable diseases in Europe 2009. Stockholm: ECDC. Revised edition. 2010 Jun: 1-221. Available from: http://www.ecdc.europa.eu/en/publications/Publications/0910_SUR_Annual_Epidemiological_Report_on_Communicable_Diseases_in_Europe.pdf

ECDC (European Centre for Disease Prevention and Control). 2010d. Annual epidemiological report on communicable diseases in Europe 2010. Stockholm: ECDC, pp. 1-181. Available from: http://www.ecdc.europa.eu/en/publications/Publications/1011 SUR_Annual_Epidemiological_Report_on_Communicable_Diseases_in_Europe.pdf\#page $=25$

ECDC (European Centre for Disease Prevention and Control). 2011a. Annual epidemiological report 2011. Reporting on 2009 surveillance data and 2010 epidemic intelligence data. Stockholm: ECDC, pp. 1-227. Available from: http://www.ecdc.europa.eu/en/ publications/Publications/1111_SUR_Annual_Epidemiological_ Report_on_Communicable_Diseases_in_Europe.pdf ECDC (European Centre for Disease Prevention and Control). 2011b. Influenza surveillance in Europe 2010-2011. Stockholm: ECDC. 2011 Dec; 1-15. Available from: http://www.ecdc.europa. eu/en/publications/Publications/111209_SUR_Influenza_surveillance_Europe\%20_2010_2012.pdf
EISS (European Influenza Surveillance Scheme). 2006. Annual report 2004-2005 influenza season. Utrecht, the Netherlands, NIVEL, pp. 1-60. Available from: http://www.euroflu.org/documents/eiss_annual_report_2004-2005_+_cover.pdf

Fleming D.M., J. van der Velden and W.J. Paget. 2003. The evolution of influenza surveillance in Europe and prospects for the next 10 years. Vaccine 21(16): 1749-1753.

Murphy B.R and R.G. Webster. 1996. Orthomyxoviruses, pp. 1397 1445. In: Fields B.N. (ed). Fields Virology. Raven, New York.

Neumann G. and Y. Kawaoka. 2011. The first influenza pandemic of the new millennium. Influenza Other Respir. Vir. 5(3): 157-166.

Nguyen-Van-Tam JS. 1998. Epidemiology of influenza, pp. 181-206. In: Nicholson K.G., R.G. Webster and A.J. Hay (eds). Textbook of influenza. Blackwell Science Ltd.

Paget J., R. Marquet, A. Meijer and K. van der Velden. 2007. Influenza activity in Europe during eight seasons (1999-2007): an evaluation of the indicators used to measure activity and an assessment of the timing, length and course of peak activity (spread) across Europe. BMC Infect. Dis. 7: 141.

Romanowska M., I. Nowak, K. Rybicka and L.B. Brydak. 2008a. The introduction of the SENTINEL influenza surveillance system in Poland - experiences and lessons learned from the first three epidemic seasons. Euro Surveill. 13(8): 50-56.

Romanowska M., I. Nowak and L.B. Brydak. 2008b. Activity of influenza virus and other viruses of respiratory tract infections in Poland in the epidemic season 2007/2008 (in Polish). Family Med. Prim. Care Rev. 10: 638-640.

Romanowska M., M.P. Czarkowski, I. Nowak, E. Staszewska, S. Donevski and L.B. Brydak. 2010. Influenza in Poland in 2008 (in Polish). Przegl. Epidemiol. 64: 175-179.

Webster R.G., W.J. Bean, O.T. Gorman, T.M. Chambers and Y. Kawaoka. 1992. Evolution and ecology of influenza A viruses. Microbiol. Rev. 56: 152-179.

WHO (World Health Organization). 2010. Recommended viruses for influenza vaccines for use in the 2010-2011 northern hemisphere influenza season. Weekly Epid. Rec. 10: 81-92.

WHO (World Health Organization). 2011a. Manual for the laboratory diagnosis and virological surveillance of influenza. WHO Global Influenza Surveillance Network, pp. 1-140.

WHO (World Health Organization). 2011b. Review of the 20102011 winter influenza season, northern hemisphere. Weekly Epid. Rec. 22: 222-227. 